\title{
EL USO DE NARRACIONES PARA ESTUDIAR LA INFLUENCIA INTERLINGÜÍSTICA EN LA PRODUCCIÓN DE APRENDICES NORUEGOS DE ESPAÑOL COMO L3
}

\section{Víctor Manteiga \\ Universidad del Sureste de Noruega}

\section{Resumen}

La influencia interlingüística (IIL) en la mente de los hablantes es una de las piezas fundamentales para comprender los procesos cognitivos de aprendizaje y producción de una segunda o sucesiva lengua. En este artículo se exponen ciertos aspectos metodológicos y cognitivos de la extracción de narraciones escritas para investigar fenómenos de IIL en la producción de lenguas extranjeras. El método se ilustra con un estudio de transferencia interlingüística en la producción de textos escritos por estudiantes de español L3 en institutos de bachillerato noruegos. Los resultados del análisis apuntan a retos para superar conceptualizaciones altamente afianzadas por el uso de la L1 y la L2 que dificultan la expresión de ciertas representaciones mentales durante la producción de la L3, en concreto las que involucran el uso de verbos de movimiento (ej. "ir", "saltar", "entrar", etc.).

Palabras clave: Narración; Influencia interlingüística; Transferencia conceptual; Tipología lingüística; ELE en Noruega; Adquisición de terceras lenguas; Verbos de movimiento; Método de diagnóstico.

\section{Introducción}

La narración ocupa un lugar central en la comunicación humana y, por ello, siempre ha atraído la atención de disciplinas científicas interesadas tanto en las prácticas culturales de los pueblos como en el uso y la adquisición de lenguas (Pavlenko, "Narrative Analysis"). Efectivamente, narrar está tan profundamente ligado a la experiencia humana que, como dijo Roland Barthes, está presente en todas las épocas, en todos los lugares, en todas las sociedades; la narración comienza con la 


\section{Nordic Journal of Modern Language Methodology}

Temanummer: Spansk i Norge og det norske i den spansktalende verden.

historia misma de la humanidad (237, mi traducción). Contar historias es fundamental para el establecimiento y el desarrollo de las sociedades, y la evolución natural de nuestra especie nos ha dotado de mecanismos para poder reconstruir nuestras experiencias sensoriales en forma de conceptos, almacenarlos en la memoria a largo plazo, y comunicarlos lingüísticamente.

El valor metodológico fundamental de la narración para la investigación científica radica en que los textos narrativos surgen del uso de la lengua en contexto y, por lo tanto, revelan propiedades lingüísticas que solo emergen durante la producción del discurso conexo. Se puede decir, pues, que la narrativa abre una ventana a los mecanismos mentales involucrados en el procesamiento lingüístico, sea éste de lenguas nativas o extranjeras.

El objetivo de este artículo es proponer la extracción de narraciones como método válido para la identificación y la comprensión de retos fundamentales en el aprendizaje y el uso de segundas y terceras lenguas. Para ello, presentaré, en primer lugar, varias consideraciones teóricas y metodológicas esenciales; en segundo lugar, ilustraré el método con un estudio de influencia interlingüística en la producción de español como L2 y L3. La investigación se centra en la producción escrita de narraciones por parte de aprendices de español y/o inglés como lengua extranjera, y cuyas lenguas nativas son el noruego, el inglés, y el español. Más detalles sobre los participantes y el proceso de extracción se detallan más abajo.

\section{Variedad individual y homogeneidad grupal}

Para elaborar una narración, un hablante tendrá que decidir qué aspectos de la historia incluir, con qué grado de detalle describirlos, y en qué orden presentarlos. Diferentes hablantes harán todas estas cosas de forma distinta, aún cuando se trate de la narración del mismo evento, así que los diversos textosf contarán con cierto grado de variedad individual y resultarán, por lo tanto, en versiones de los hechos. A modo de ejemplo de tal variedad, fijémonos en las siguientes narraciones de la misma escena que tres estudiantes escribieron siguiendo las mismas instrucciones: 
Temanummer: Spansk i Norge og det norske i den spansktalende verden.

(1) Un chico y una chica preparamos comida. El chico tiene pelo corto y negro, y la chica tiene pelo blanco. Un perro está en la bolsa, y el chico y la chica no sé. La comida no está allí.

(2) Un día, un chico y una chica están en la cocina. La chica hace la pan y el chico está con los pasteles. El perro es en la table y está mirando para la comida. Los niños dicen hola a otra persona en la calle. Los niños encontran un lugar para comer sus comida. Los niños miran en la caja $y$ encontran el perro. El perro juega.

(3) Un día había una familia, y los dos hermanos estaban preparando la comida y la merienda para irse de picnic. Mientras que los dos hermanos terminaron de meter la comida en la cesta la madre los llamó, y mientras que la madre les explicaba por dónde era el camino con un mapa, el perro se metió dentro de la cesta. Cuando los hermanos salieron de casa y llegaron a la colina, se sentaron para comerse lo que habían preparado y de repente se dieron cuenta de que el perro estaba dentro de la cesta y se había comido la merienda.

Los textos se escribieron bajo las mismas condiciones experimentales, y los autores tenían la misma edad y pertenecían a contextos geográficos y socioeconómicos similares (todos ellos eran estudiantes de niveles educativos equivalentes en colegios de contextos urbanos europeos). Como cabría esperar, los tres textos tienen mucho en común. Por ejemplo, en las tres narraciones se habla de comida, de un perro, y de algún tipo de contenedor (bolsa, caja, cesta). Por otra parte, las diferencias existentes que se pueden observar tampoco son de extrañar, pues se sabe que personas diferentes tienen respuestas distintas ante una misma experiencia en función de sus preferencias, sus recuerdos y sus historias personales. En este caso, los autores de las narraciones se diferenciaban en un aspecto crucial: el bagaje lingüístico de cada uno de ellos. Así, el autor de (1) es hablante de noruego L1, inglés L2, y español L3; el autor de (2) es hablante de inglés L1 y español L2; el autor de (3) es hablante de español L1 y de inglés L2.

Para un análisis comparativo adecuado de los textos hay que conocer los repertorios lingüísticos de los hablantes, porque la tarea de escribirlos supone retos comunicativos y cognitivos distintos para hablantes de una L1, una L2, y una L3. Así, un análisis microtextual revela que, por ejemplo, la verbosidad es mayor en el texto producido por el hablante nativo (101 palabras en (3)) que en los textos de los aprendices de español como L3 (40 en (1)) y L2 (68 en (2)). También vemos que 


\section{Nordic Journal of Modern Language Methodology}

Temanummer: Spansk i Norge og det norske i den spansktalende verden.

sólo el hablante nativo ha producido oraciones complejas y proposiciones subordinadas, y además encontramos errores morfosintácticos en (1) y en (2), así como una inserción léxica ("table") de la L1 en (2). En el nivel macrotextual también hay diferencias claras. Por ejemplo, en (1), se describe a los protagonistas ("el chico tiene pelo corto y negro, y la chica tiene pelo blanco"), no así en (2) y (3). En (3) se menciona el propósito de la actividad de los niños ("para irse de pícnic"), pero no en las otras narraciones. De hecho, un análisis detallado nos revelaría diferencias en cuatro niveles de la planificación de la macroestructura: selección, segmentación, estructuración y alineación (Von Stutterheim \& Nüse). Tales observaciones sugieren diferencias en el reparto de la atención durante la elaboración del mensaje, lo cual no es baladí porque, tanto lo que se expresa, como la manera en que se organiza la información, determinan directamente qué estructuras lingüísticas necesitará el hablante (Talmy, "Attention Phenomena").

Dado que, como acabamos de ver, las narraciones extraídas con un mismo estímulo visual hacen obvias las similitudes y las diferencias en la producción lingüística de diferentes personas, cabe hacerse varias preguntas: ¿hasta qué punto las diferencias son derivadas de la cognición individual (personalidad, intereses, etc.), y hasta qué punto se deben al proceso de socialización en una(s) lengua(s) en concreto? Como nos recuerdan varios autores (véase, por ejemplo, Jarvis, "Clarifying the Scope of Conceptual Transfer"), las diferencias personales producen efectos cognitivos y lingüísticos predecibles según los antecedentes de los individuos, especialmente los basados en la edad, el género, el estatus socioeconómico, la formación, el grado de experiencia, etc. Por lo tanto, si se puede agrupar a los individuos según estas variables, las diferencias individuales pasarían a ser diferencias grupales. ¿Hasta qué punto se puede hallar diferencias representativas de las tendencias en hablantes nativos de las mismas lenguas? Todas estas cuestiones radican en el núcleo de interés de la investigación en influencia interlingüística. 
Nordic Journal of Modern Language Methodology

2019, 7 (2), 89-119 Peer reviewed Temanummer: Spansk i Norge og det norske i den spansktalende verden.

\section{La influencia interlingüística (IIL)}

La IIL es uno de los factores fundamentales involucrados en el aprendizaje de una lengua extranjera, y se puede definir como el proceso por el cual el conocimiento de una lengua afecta al uso o al conocimiento de otra lengua (Jarvis \& Pavlenko). Los fenómenos derivados de la IIL se deben a que todo nuevo aprendizaje ocurre sobre la base de lo ya aprendido. Así, cuando una persona comienza la adquisición de una nueva lengua, usará los conocimientos de sus otras lenguas para impulsar el aprendizaje. La IIL es objeto de estudio de investigadores en multilingüismo, adquisición de segundas lenguas, y lingüística aplicada desde hace décadas, y la extensión e importancia de los hallazgos van más allá de lo que permite este artículo (para un resumen excelente véase, por ejemplo, Jarvis \& Pavlenko). No obstante, me detendré un momento en los requisitos generalmente aceptados hoy en día para poder decir con alto grado de certeza que la observación de un fenómeno lingüístico específico es un caso de IIL.

\section{Identificación y evidencia de IIL}

A menudo se explican los errores gramaticales en una lengua extranjera aludiendo a que en la lengua nativa "se dice así". Tanto las intuiciones de los profesores como la introspección de los lingüistas nos pueden parecer muy certeras en general, pero lo cierto es que el criterio de "cuando lo veo lo reconozco" es susceptible de crítica por confiar en impresiones subjetivas. Por ello se requiere un enfoque metodológico más riguroso para la identificación de casos de IIL. Tres tipos de evidencia, propuestos inicialmente por Jarvis ("Methodological Rigor in the Study of Transfer: Identifying L1 Influence in the Interlanguage Lexicon"), gozan de gran aceptación hoy en día como indicios claros de IIL: homogeneidad grupal, heterogeneidad intergrupal, y congruencia de actuación interlingüística.

La evidencia de homogeneidad grupal satisface la exigencia de demostrar que un comportamiento lingüístico en concreto no es un caso aislado, sino que ilustra una tendencia en un grupo de individuos con el mismo repertorio lingüístico. De esta forma, nos aseguramos de que un fenómeno observado en la producción 


\section{Nordic Journal of Modern Language Methodology}

Temanummer: Spansk i Norge og det norske i den spansktalende verden.

lingüística de un hablante no se debe a idiosincrasias de la cognición de ese individuo. La heterogeneidad intergrupal, por su parte, garantiza que el fenómeno lingüístico no sea algo que los hablantes de cualquier otro repertorio lingüístico produzcan y que, por lo tanto, se deba específicamente al conocimiento de alguna de las lenguas de los hablantes en cuestión. Finalmente, la congruencia de actuación interlingüística exige que un hablante haga lo mismo en todas sus lenguas, lo cual nos indicaría que el fenómeno lingüístico está motivado por tendencias en el uso de la lengua, y no por otros factores. Aportar los tres tipos de evidencia añaden peso a las conclusiones en un estudio de IIL (Jarvis \& Pavlenko 36).

\section{El uso de narraciones para estudiar la IIL}

Los métodos para estudiar los efectos de la IIL son de varios tipos. Los más comunes se clasifican en aquellos de tipo psicolingüístico, por una parte, y los de tradición intercultural por otra (Pavlenko, "Conceptual Representation in the Bilingual Lexicon and Second Language Vocabulary Learning"). El uso de narraciones entra dentro del segundo tipo y, como ya se ha señalado, presenta la ventaja de que permite observar del uso de la lengua en contexto. Este método ha obtenido importantes resultados para entender la interacción de diversas combinaciones de lenguas en la mente de los hablantes. Un buen ejemplo lo encontramos en Odlin \& Jarvis, que extrajeron narraciones basadas en el visionado de "Tiempos Modernos" de Chaplin para estudiar la IIL en la adquisición del inglés como lengua extranjera por parte de hablantes bilingües de finés y sueco. También hay estudios de este tipo realizados con hablantes bilingües nativos de español y catalán (Sánchez), y de español y vasco (Cenoz) que tienen alemán, francés, o inglés como lenguas extranjeras. En cuanto al español como lengua extranjera, hay estudios de IIL en hablantes con varios repertorios lingüísticos que incluyen el portugués brasileño (Dietrich), el danés (Cadierno), y el sueco (Donoso), entre otros. 
Nordic Journal of Modern Language Methodology

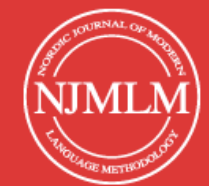

2019, 7 (2), 89-119 Peer reviewed Temanummer: Spansk i Norge og det norske i den spansktalende verden.

\section{Extracción de narraciones: aspectos cognitivos y metodológicos}

Narrar requiere muchas operaciones mentales que se realizan mediante la interacción de varios sistemas cognitivos, incluido el propio sistema cognitivo narrativo (Talmy, Toward a Cognitive Semantics 419, Vol. II). Por ejemplo, el hablante tiene que establecer un contenido conceptual y estructurarlo de acuerdo con las convenciones lingüísticas y culturales pertinentes para evocar la sensación de progresión en el desarrollo de los acontecimientos. Otro ejemplo es el de tener que proporcionar un grado alto de coherencia y de cohesión para permitir una reconstrucción holística de la historia. Estas tareas cognitivas afectan directamente al uso de la lengua, ya que el contenido conceptual se verá reflejado en estructuras lingüísticas específicas.

La habilidad de narrar se adquiere de forma gradual durante las diferentes etapas del desarrollo. Así, los niños de entre 3 y 4 años tienden a referirse a escenas aisladas en vez de construir historias cohesivas (Pearson \& de Villiers), pero algo más tarde, entre los 5 y los 7 años, la secuenciación cronológica de los eventos se hace más habitual, con saltos cualitativos de los 4 a los 5 , y de los 6 a los 7 años. El uso de conectores ("y", "entonces") también aumenta en el período prescolar (Peterson \& McCabe) y la expresión lingüística de eventos correctamente formados de manera global no ocurre normalmente hasta los 9 o los 10 años. Además, la destreza en la expresividad retórica se consolida durante la adolescencia (Licandro 28). En lo que se refiere a las lenguas extranjeras, las limitaciones de competencia lingüística de la L2 se ven compensadas, en el caso de hablantes más maduros en comparación con otros más jóvenes, precisamente por su mayor sofisticación a la hora de incluir elementos informativos tanto del fondo como de la figura de las escenas, y de otros acontecimientos del relato (Minami 92). También la edad es un factor importante para la comprensión del estilo retórico de la L2 (Doiz \& Lasagabaster), y, en la modalidad escrita, para desarrollar la competencia comunicativa de aspectos tales como la organización textual, la complejidad de las oraciones, y la influencia interlingüística de la L1 (Lasagabaster \& Doiz). 
Temanummer: Spansk i Norge og det norske i den spansktalende verden.

Desde el punto de vista metodológico de la extracción de narraciones, hay que tener en cuenta que nuestra forma de proceder durante la intervención puede repercutir en el procesamiento cognitivo de los aprendices y, con ello, afectar su producción lingüística. Por ejemplo, darles o no darles tiempo para planificar la narración resultará en diferentes cargas procedimentales y, por lo tanto, en diferentes comportamientos lingüísticos (Saeedi). También hemos de pensar que facilitar el acceso al estímulo visual mientras cuentan o escriben las narraciones requerirá menor esfuerzo a la memoria que si se les retira el estímulo y tienen que recordarlo (Pavlenko, "Narrative Analysis" 313). Además, usar temas familiares facilitará los procesos de categorización y activación de conceptos, así como el uso de las estructuras lingüísticas asociadas. Asimismo, dar las instrucciones de la tarea en una lengua $u$ otra activará en el aprendiz un modo lingüístico específico (Grosjean), y hasta el propio contenido de las instrucciones puede activar ciertas estructuras y dominios conceptuales en vez de otros. También el tipo de tarea y el instrumento son factores importantes cuando se utiliza este método de extracción lingüística. Por ejemplo, una serie de viñetas compuesta por una secuencia cronológica clara permitirá al aprendiz asociar las relaciones de causa-efecto con mayor facilidad, lo cual resultará en un uso de la lengua más preciso y fluido que en el caso de una composición laxa de los acontecimientos (Tavakoli \& Foster). Asimismo, una historia con eventos paralelos en diferentes planos de acción estimulará el uso de estructuras más complejas, tales como proposiciones subordinadas que permitan establecer relaciones entre planos (Foster \& Tavakoli).

Aparte de estos factores cognitivos y metodológicos es útil plantearse una hipótesis inicial o pregunta de investigación, y diseñar la intervención para que facilite el estímulo de las estructuras mentales y lingüísticas que nos interesen. También hay que crear condiciones de laboratorio específicas para que la actividad sea replicable, especialmente si queremos comparar más de un grupo de aprendices. Con ello nos aseguramos de que todos hayan tenido las mismas condiciones contextuales y minimizamos diferencias producidas por influencias del entorno. Además, es importante crear grupos comparables de acuerdo con la edad, el bagaje lingüístico, el estatus socioeconómico, la competencia lingüística, etc. Así, 


\section{Nordic Journal of Modern Language Methodology}

Temanummer: Spansk i Norge og det norske i den spansktalende verden.

comparar la producción lingüística de aprendices urbanos y aprendices rurales no es tan válido como comparar grupos del mismo ámbito geográfico y social, de la misma forma que es recomendable tratar aparte a los hablantes nativos bilingües de otras lenguas. Finalmente, hay que evitar el efecto de la práctica cuando le pedimos a los mismos aprendices que realicen la tarea dos veces en lenguas distintas. Para mitigar el efecto se puede esperar dos semanas antes de la segunda extracción, o bien se puede dividir el grupo en dos y pedirle a una mitad que lo haga primero en la lengua A y después en la lengua $B$, mientras que a la otra mitad se le pide el orden de lenguas inverso.

\section{Un ejemplo del método en uso: IIL en eventos de movimiento}

Con el fin de ilustrar el método descrito, presento a continuación un estudio de la IIL en la producción narrativa de hablantes nativos de noruego, inglés, y español, todos ellos aprendices de inglés y/o español como lengua extranjera. Aunque este estudio forma parte de un proyecto de investigación que incluye objetivos más amplios, por motivo de espacio sólo se incluyen aquí los datos relevantes para ilustrar la aplicación del método. Tras una breve introducción a los retos generales para un aprendiz durante la producción lingüística de su L2 y su L3, así como a los verbos de movimiento, presento las preguntas de investigación, el método, y una discusión de los resultados. Finalmente, la sección encabezada con el título Conclusiones ofrece una reflexión sobre la utilidad del método según se ha presentado e ilustrado en la globalidad del artículo.

\section{Retos cognitivos en la producción de L2 y L3}

El uso de una lengua extranjera se caracteriza, entre otras cosas, por ser un reto lingüístico y cognitivo mayor que el de usar la lengua nativa. La magnitud y el tipo de dificultades depende de múltiples factores (p. ej., la motivación y el contexto de adquisición), pero se resumen en tener que producir estructuras lingüísticas correctas y con fluidez al usar un sistema lingüístico poco automatizado que compite con patrones de atención ya aprendidos y estables (Ellis \& Wulff). Por eso las estructuras de las lenguas previamente adquiridas sirven de soporte e influyen directamente en la 


\section{Nordic Journal of Modern Language Methodology}

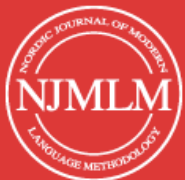

2019, 7 (2), 89-119 Peer reviewed

Temanummer: Spansk i Norge og det norske i den spansktalende verden.

producción de la lengua meta: la activación de estructuras fuertemente afianzadas interviene si éstas no son inhibidas, produciéndose fenómenos de IIL. Hay que recordar que la IIL no está limitada al influjo de la lengua nativa, sino que las otras lenguas pueden ser la fuente de la IIL (Jarvis \& Pavlenko 28) y de ahí la importancia de diferenciar los casos de L2 de los de L3 (De Angelis).

Ciertamente, cuando las lenguas tienen características comunes, la IIL puede resultar en estructuras lingüísticas correctas en la lengua meta y, por lo tanto, en transferencia positiva (Odlin 36). Sin embargo, hemos de recordar que los casos de IIL que más frecuentemente se suelen identificar son aquellos que surgen de diferencias entre las lenguas y resultan en errores de actuación, es decir, en casos de transferencia negativa. Es crucial recordar aquí que también se dan casos de ILL que resultan atípicos en la lengua meta, pero que no son estrictamente casos de transferencia negariva. Estos tipos de IIL son más difíciles de detectar, porque pueden involucrar casos de transferencia conceptual (Jarvis, "Theoretical and Methodological Issues in the Investigation of Conceptual Transfer"; Jarvis, "Clarifying the Scope of Conceptual Transfer"), los cuales suelen escapar a la conciencia. En estos casos, el reto cognitivo es el de usar estructuras de la lengua meta sin que el sistema conceptual derivado del conocimiento de las otras lenguas intervenga y afecte el proceso, 0 , dicho en otras palabras, el reto es adquirir fluidez conceptual (Danesi).

\section{Tipología de la expresión de eventos de movimiento}

La tipología lingüística tiene mucho que decir al respecto de la IIL, puesto que lenguas tipológicamente similares producen más ejemplos de transferencia positiva (Jarvis \& Pavlenko 176-177), y se han identificado rasgos lingüísticos cuya transferencia entre lenguas de diferentes grupos tipológicos puede resultar problemática, entre ellos, la expresión de eventos de movimiento. El estudio de la expresión lingüística de eventos de movimiento nos refiere a una de las distinciones tipológicas más influyente en la lingüística moderna, a saber, la que distingue entre "Satellite-framed languages" (SFL) y "Verb-framed languages" (VFL), propuesta en primer lugar por Leonard Talmy (Toward a Cognitive Semantics). Movimiento se ha de entender aquí como un "cambio de localización desde una posición inicial $A$, 


\section{Nordic Journal of Modern Language Methodology}

Temanummer: Spansk i Norge og det norske i den spansktalende verden.

hasta una posición final $B$, por la cual la figura móvil localizada en la posición $A$ en el momento T1, pasa a estar en la posición B en el momento T2" (Filipovic \& IbarretxeAntuñano 527, mi traducción). Los elementos que intervienen en un evento de movimiento en este sentido son la figura, el fondo, la trayectoria, y el destino: la figura se mueve relativa al fondo a lo largo de una trayectoria hasta llegar a un destino.

Las SFL, a las que pertenecen el noruego y el inglés, y las VFL, entre las que se incluye el español, se diferencian en la tendencia a seleccionar diferentes aspectos de los eventos de movimiento para su expresión lingüística, o bien a estructurarlos de forma distinta. Las SFL suelen expresar la trayectoria con partículas o satélites, normalmente preposiciones. Estas lenguas, además, tienden a expresar la manera del movimiento en la raíz del verbo principal. Las VFL, por su parte, prefieren expresar la manera con cláusulas adverbiales o gerundios. Lo que el verbo suele expresar en este tipo de lenguas es la trayectoria del movimiento. Veamos unos ejemplos:

(4) Inglés (SFL): The boy ran into the room.

(5) Noruego (SFL): Gutten løp inn i rommet.

(6) Español (VFL): El niño entró en la habitación corriendo.

Tanto (4) como (5) expresan en el verbo ("ran", "løp") la manera en que se desarrolla el movimiento, es decir, la manera de desplazarse en el espacio. Al mismo tiempo, la trayectoria del movimiento (desde el exterior hasta el interior de una habitación) está expresada en el satélite mediante las cláusulas preposicionales "into" y "inn i". En español (6) la información se estructura de forma diferente: el verbo "entrar" expresa la trayectoria del movimiento, mientras que la manera viene dada por el gerundio "corriendo".

\section{Preguntas de investigación}

Para explorar las diferencias entre las SFL y las VFL en relación con el proceso de adquisición de español como L2 y L3 por hablantes nativos de inglés y noruego 


\section{Nordic Journal of Modern Language Methodology}

Temanummer: Spansk i Norge og det norske i den spansktalende verden.

respectivamente, así como la adquisición del inglés como L2 por hablantes nativos de español y noruego, se han formulado las siguientes preguntas de investigación:

P1. ¿Habrá diferencias en los patrones de atención durante la producción lingüística en la lengua nativa L1?

P2. ¿Habrá IIL en la atención que cada grupo preste a la escena cuando usen la L2 o la L3?

P3. ¿Habrá diferencias en la frecuencia de uso de verbos de movimiento en los tres grupos cuando usen la L1?

P4. ¿Habrá IIL en la frecuencia de uso de verbos de movimiento cuando usen la L2 o la L3?

P5. En los casos de uso de verbos de movimiento, ¿expresará cada grupo la trayectoria y la manera de movimiento de forma diferente en su L1?

P6. ¿Habrá IIL en la expresión de la trayectoria y la manera de movimiento cuando usen la L2 o la L3?

\section{Metodología}

Para este proyecto se han creado varios corpus de narraciones escritas por hablantes de noruego L1, inglés L1, y español L1. Los corpus se componen de textos narrativos en todas las lenguas nativas y no-nativas de los participantes. Todos ellos eran alumnos de estudios preuniversitarios (Bachillerato y $4^{\circ}$ de la ESO en España, Key Stage 5 en Inglaterra, y Videregående en Noruega). La media de edad era de 16,5 años en el grupo de español L1 y 17 años en los demás. Los participantes eran comparables en cuanto a su estatus socioeconómico, y los centros educativos en los que estudiaban se encuentran situados en zonas urbanas de España, Inglaterra, y Noruega.

Uno de los objetivos del diseño de la tarea era que se asemejara lo máximo posible a una actividad ordinaria de clase, motivando con ello un uso de la lengua similar al de su día a día como aprendices. Por ello, la recogida de datos se hizo en las aulas donde los participantes normalmente tenían sus clases de lengua extranjera. Además, para minimizar posibles efectos de reactividad psicológica ( $p$. 
Temanummer: Spansk i Norge og det norske i den spansktalende verden.

ej., el Efecto Hawthorne, por el cual los sujetos de un estudio modifican su comportamiento habitual al saber de la presencia del investigador), fueron los propios profesores de los participantes quienes realizaron la actividad. Todos eran docentes titulados y experimentados, y fueron instruidos para crear condiciones de laboratorio idénticas y para secuenciar la tarea de la misma forma, incluyendo las instrucciones y la resolución de posibles dudas por parte de los participantes. La tarea era la siguiente: "Mira la secuencia con atención y escribe la historia que cuenta. Tienes 10 minutos". Los participantes no tenían acceso a ningún tipo de material de consulta, y escribieron las narraciones en una hoja de papel.

Las narraciones se hicieron tanto en la $L 1$ como en la L2, salvo los nativos noruegos que aprenden español L3, quienes solo produjeron narraciones en español para evitar el efecto de la práctica excesiva. Por lo tanto, fue otro grupo de nativos noruegos el que aportó los corpus de control en noruego L1 e inglés L2. La producción de L3 no se aplica en el caso de los nativos de inglés y español (véase tabla 1). Para mitigar posibles efectos de la repetición y del orden de las lenguas, la mitad de los aprendices en cada grupo escribió la narración primero en una lengua, y después en la otra; la otra mitad del grupo lo hizo en el orden de lenguas inverso.

El instrumento para la extracción de las narraciones fue la secuencia de viñetas titulada "The Dog Story" (Heaton) (ver anexo). La elección de este estímulo visual se fundamenta en varias de sus características inherentes, así como en la validación de su uso en la literatura (véase, p. ej., Sánchez \& Jarvis; Tavakoli \& Foster). La historia cuenta cómo dos niños preparan comida para un pícnic mientras un perrito les observa; tras una excursión al campo, se sientan a comer y descubren que el perro se había colado en la cesta y se había comido todo. Los aprendices tuvieron acceso a las imágenes durante toda la actividad. Para validar las comparaciones entre los aprendices de español ingleses y noruegos, ambos grupos hicieron una prueba de nivel de español. Los resultados mostraron un nivel parecido, tan solo ligeramente superior en el grupo de aprendices inglés. En general, los dos grupos obtuvieron resultados que los sitúan en el A2 del Marco Común Europeo de Referencia para las lenguas. Los aprendices de inglés L2 noruegos y españoles no hicieron test de nivel, pero sus profesores confirmaron un nivel C1 para ambos. 
Nordic Journal of Modern Language Methodology

Temanummer: Spansk i Norge og det norske i den spansktalende verden.

\begin{tabular}{ccccc}
\hline L1 & L2 & L3 & Participantes & $\begin{array}{c}\text { Lengua de las } \\
\text { narraciones }\end{array}$ \\
\hline Noruego & Inglés & Español & 66 & Español L3 \\
\hline Noruego & Inglés & --- & 29 & Noruego L1; Inglés L2 \\
\hline Inglés & Español & --- & 24 & Inglés L1; Español L2 \\
\hline Español & Inglés & --- & 41 & Español L1; Inglés L2 \\
\hline
\end{tabular}

Tabla 1. Participantes, su repertorio lingüístico, y lenguas en las que escribieron las narraciones.

La escena meta seleccionada para el análisis es la que muestra a los niños cuando descubren al perrito dentro de la cesta, y más específicamente, la relación entre el perrito y la cesta. Los pasos del análisis fueron los siguientes: 1) identificación en el corpus de todas las menciones explícitas a la escena que describan al perrito con relación a la cesta o su contenido; 2) de éstas, cálculo de cuántas se refieren a la escena como un evento de movimiento; 3) identificación de los patrones de referencia a la manera y la trayectoria del movimiento. 4) Por último, se hicieron comparaciones interlingüísticas de lo hallado en 1), 2), y 3 ).

\section{Resultados}

Para responder las preguntas, miramos las frecuencias en el corpus, y comparamos la media entre grupos y entre lenguas, así como entre tipologías lingüísticas (SVL vs VFL). Los resultados se ofrecen a continuación estructurados según el orden de las preguntas propuesto en 5.3 .

\section{P1. ¿Habrá diferencias en los patrones de atención en la lengua nativa L1?}

Asumimos aquí que la frecuencia con que se selecciona una escena para su expresión lingüística refleja su saliencia relativa, es decir, la capacidad de esa parte del estímulo para captar la atención de los hablantes. Así, si más del $50 \%$ de los aprendices de un grupo la menciona explícitamente en sus narraciones, podremos decir que la escena es saliente o prominente. Por lo tanto, la saliencia de una escena no se define en relación a otras escenas de la historia, sino en relación al 


\section{Nordic Journal of Modern Language Methodology}

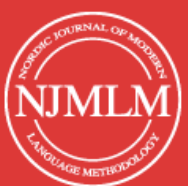

2019, 7 (2), 89-119 Peer reviewed Temanummer: Spansk i Norge og det norske i den spansktalende verden.

número de hablantes que las incluyen en sus narraciones. Los resultados del análisis muestran que, efectivamente, la escena es percibida como prominente en la historia, pues la mayoría de los hablantes en cada grupo la menciona (español L1 = 59\%; noruego L1 = 79\%; inglés L1 = 88\%). Sin embargo, vemos que esta escena parece ser más saliente para los nativos ingleses y noruegos que para los españoles, lo cual sugiere una diferencia inter-tipológica en los patrones de atención, bien al estímulo visual, o a la preferencia en su expresión lingüística. En su conjunto, estos meros resultados iniciales apoyan la tesis de que: a) los grupos de hablantes nativos de estas tres lenguas se parecen, pero no son idénticos en la distribución de la atención ante un mismo estímulo visual en la medida en que ésta se manifiesta en la selección de escenas para su expresión lingüística, y b) las lenguas de un mismo tipo tienden a parecerse más en la distribución de la atención al mismo estímulo que a lenguas de otros tipos (Figura 1.)

P2. ¿Habrá IIL en la atención que cada grupo preste a la escena cuando usen la L2 o la L3?

Aquí analizamos si los hallazgos de P1 se encuentran en la L2 y la L3, es decir, si hay transferencia desde la L1. Los resultados (Figura 1) indican que, pese a reducirse la frecuencia, la escena sigue siendo saliente para todos los grupos cuando realizan la tarea en la L2 y en la L3. Aunque los nativos ingleses seleccionan esta escena con menos frecuencia al hacerlo en español L2 (88\% > 79\%), siguen superando a los propios nativos españoles, es decir, cambian de lengua, pero su sistema de atención sigue sin parecerse al español. Por su parte, los nativos noruegos mencionan la escena en inglés L2 con la misma frecuencia que en noruego $L 1, y$, aunque se reduce levemente cuando realizan la tarea en español L3 (79\% > 68\%), sigue siendo superior a la de los propios nativos españoles. 


\section{Nordic Journal of Modern Language Methodology}

2019, 7 (2), 89-119 Peer reviewed

Temanummer: Spansk i Norge og det norske i den spansktalende verden.

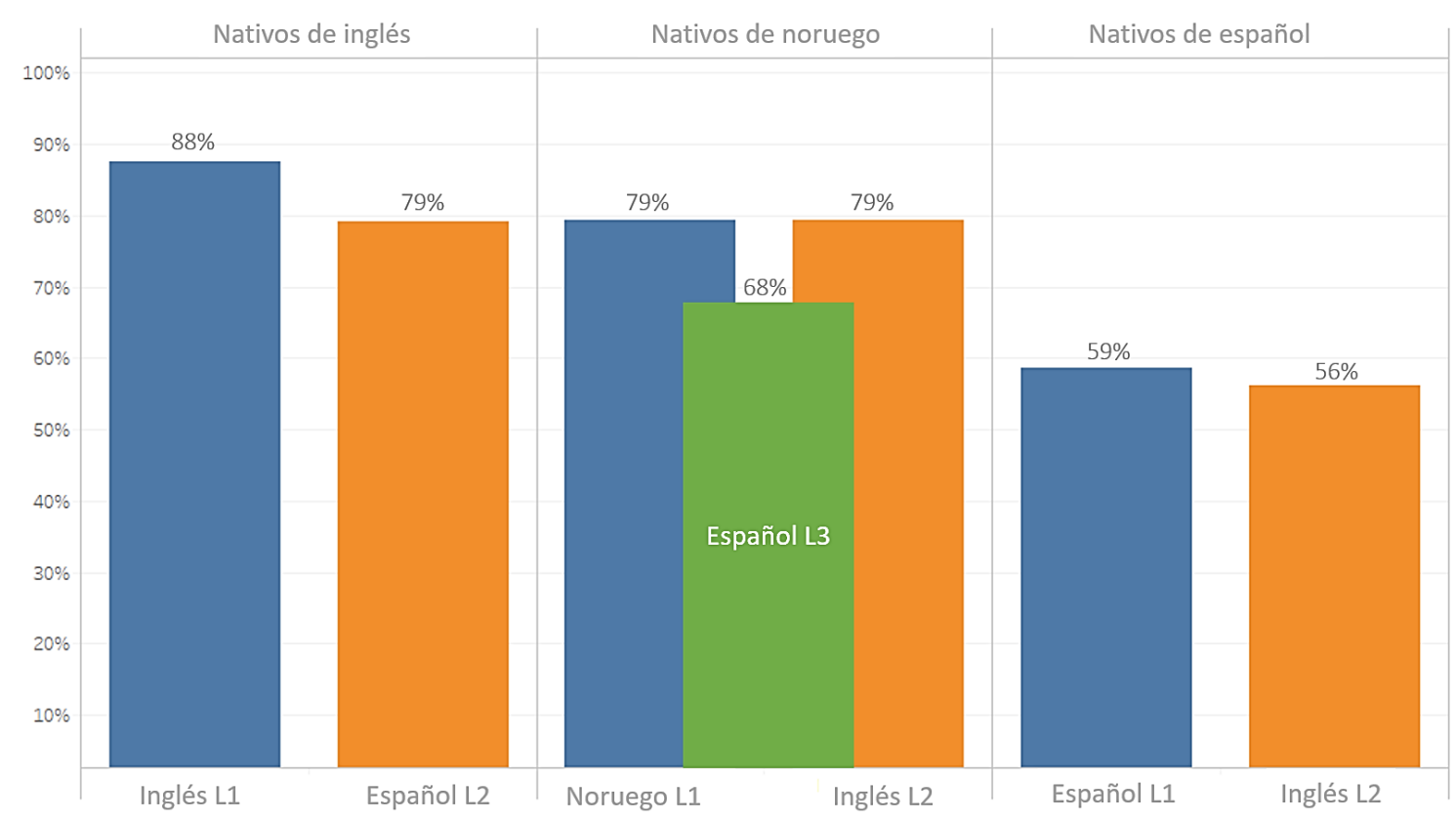

Figura 1. Media de frecuencia de menciones a la escena según L1, L2, y L3.

Los nativos españoles también transfieren los patrones de atención de su L1 cuando escriben en inglés L2, ya que la reducción en las menciones es mínima (59\% > $56 \%$ ). Si hubieran aprendido los patrones de atención más frecuentes del inglés $L 2$, habrían producido un mayor número de menciones de la escena. Los resultados en su conjunto sugieren un efecto de IIL, ya que el grado de atención prestado se transfiere de la L1 a la L2 y la L3; la diferencia inter-tipológica también se mantiene. Por otra parte, aunque hay indicios leves de que esta escena puede suponer un reto a los aprendices, y que el nivel de competencia lingüística puede afectar los patrones de selección y resultar en evitación -un tipo de transferencia negativa (Kleinmann; Laufer \& Eliasson; Odlin 39)-, no parece ser la única explicación. Lo cierto es que los aprendices noruegos y españoles de inglés L2 tienen una competencia lingüística similar, al igual que los aprendices noruegos e ingleses de español L2; por ello, el problema no parece surgir solamente por la falta de conocimiento de estructuras lingüísticas, sino que pautas de atención aprendidas y fuertemente afianzadas parecen entrar en juego también. 


\section{Nordic Journal of Modern Language Methodology}

Temanummer: Spansk i Norge og det norske i den spansktalende verden.

P3. ¿Habrá diferencias en la frecuencia de uso de verbos de movimiento en los tres grupos cuando usen la L1?

Esta pregunta indaga en la manera en que los hablantes representan conceptualmente la escena. Esto enlaza con la teoría de marcos conceptuales de C. Fillmore (2007), que entiende que el significado lingüístico depende de estructuras conceptuales organizadas y de su papel dentro de la estructura. Es posible interpretar una misma escena de diferentes maneras, es decir, en principio no hay nada en la imagen de por sí que condicione una única interpretación: cada hablante prestará atención a los aspectos de le escena que le resulten más salientes, relevantes, y dignos del esfuerzo de expresarlos lingüísticamente. En nuestro corpus, la relación del perrito con la cesta ha encontrado expresión únicamente en tres marcos conceptuales: a) un evento de movimiento (p. ej. "el perrito salió de la cesta”); b) una relación de localización estática (p. ej. "el perrito estaba dentro de la cesta"); c) la acción de comer (p. ej. "el perrito se había comido los bocadillos"). Lo que se busca en P3 es comprobar si las diferentes lenguas nativas y/o tipologías muestran diferentes tendencias a la hora de enmarcar conceptualmente la escena en la L1, es decir, si la lengua nativa es un factor a la hora de interpretar el evento. La respuesta afirmativa a esta pregunta apoyaría lo que en P1 parecíamos ver, es decir, que hablantes de lenguas nativas distintas atienden a diferentes aspectos de la misma escena que luego transfieren en su uso de la L2 o la L3. En otras palabras, no solo se presta atención a aspectos diferentes de una escena según la lengua nativa, sino que, además, se representan conceptualmente y se expresan lingüísticamente de forma diferente. 


\section{Nordic Journal of Modern Language Methodology}

2019, 7 (2), 89-119 Peer reviewed

Temanummer: Spansk i Norge og det norske i den spansktalende verden.

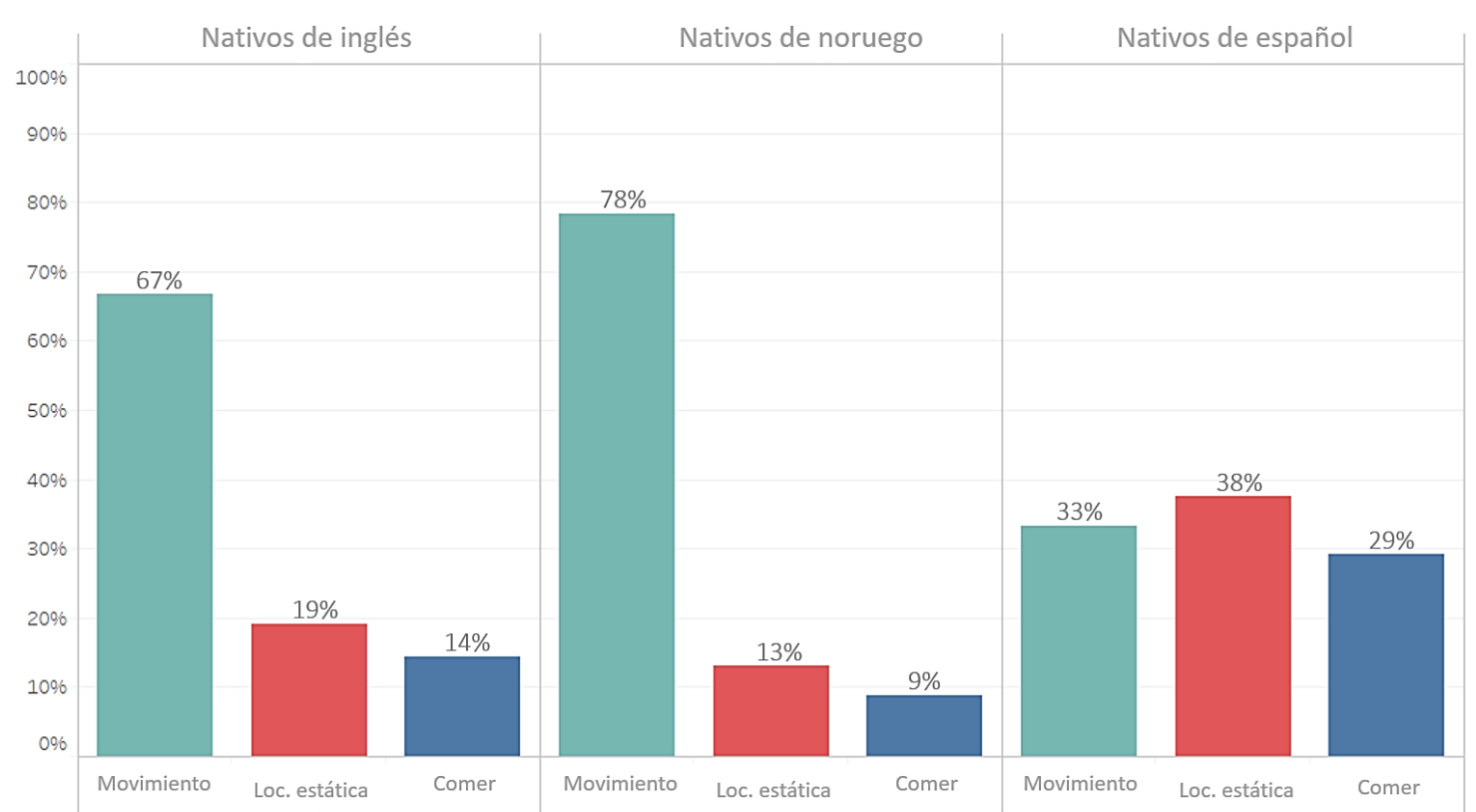

Figura 2. Marcos conceptuales para referirse a la escena. Media de menciones según la L1.

Los datos (Figura 2) muestran una preferencia clara a enmarcar la escena como un evento de movimiento en el caso del grupo nativo inglés (67\%), e incluso más pronunciada en el grupo nativo noruego (78\%). Aunque para algunos hablantes hay otros aspectos más salientes, la homogeneidad grupal es evidente. Un ejemplo representativo del corpus en noruego L1 sería el siguiente: "I det de setter seg ned hopper hunden ut av kurven" ("mientras se sentaban, el perro salió saltando de la cesta"). Un ejemplo en el corpus inglés L1 seria este: "to their surprise, their little puppy jumped out!" ("ipara su sorpresa, el cachorrito salió saltando!”). En ambos ejemplos se expresa un evento de movimiento ("Hopper ut", "jumped out"), pero hemos de recordar que no hay nada en el estímulo visual que nos lleve a pensar que el perrito salta de la cesta en vez de, por ejemplo, asomar la cabeza; se trata de contenido conceptual añadido por los hablantes.

En el caso de los hablantes nativos de español, la preferencia está en la expresión de una escena estática (38\%), por ejemplo, "Sin embargo, en vez de comida, estaba Ben", pero no es una tendencia significativa, sino que la atención a otras posibles conceptualizaciones parece estar distribuida de forma bastante homogénea en el corpus, así que también se 


\section{Nordic Journal of Modern Language Methodology}

2019, 7 (2), 89-119 Peer reviewed Temanummer: Spansk i Norge og det norske i den spansktalende verden.

pueden encontrar casos como de evento de movimiento como el siguiente: "El perro salió y no pudieron comerse la tarta".

En su conjunto, los resultados sugieren que los hablantes de lenguas SFL (inglés y noruego) se parecen mucho más entre sí en la distribución de atención a aspectos del mismo evento que a los hablantes de español y, posiblemente, otras lenguas VFL, es decir, hay evidencia de homogeneidad intra-tipológica y de heterogeneidad inter-tipológica.

P4. ¿Habrá IIL en la frecuencia de uso de verbos de movimiento cuando usen la L2 o la L3? Se explora ahora si las preferencias identificadas para la lengua nativa se dan cuando los hablantes realizan la tarea en las lenguas extranjeras, es decir, si hay IIL, o si, por el contrario, han aprendido y usado los patrones de conceptualización de la L2 y la L3. Se presentan a continuación los resultados por grupos.

El grupo de nativos ingleses (Figura 3) muestra en español L2 una distribución parecida a la de los nativos de español (ver Figura 2). Vemos que la preferencia por interpretar la escena como un evento de movimiento pasa de ser la favorita en inglés L1 (67\%) a ser la menos frecuente en español L2 (26\%). Aunque esto sugiere el posible aprendizaje exitoso de las preferencias de la lengua meta, también es posible interpretar los resultados como indicativo de evitación de la expresión de eventos de movimiento y, por lo tanto, de transferencia negativa.

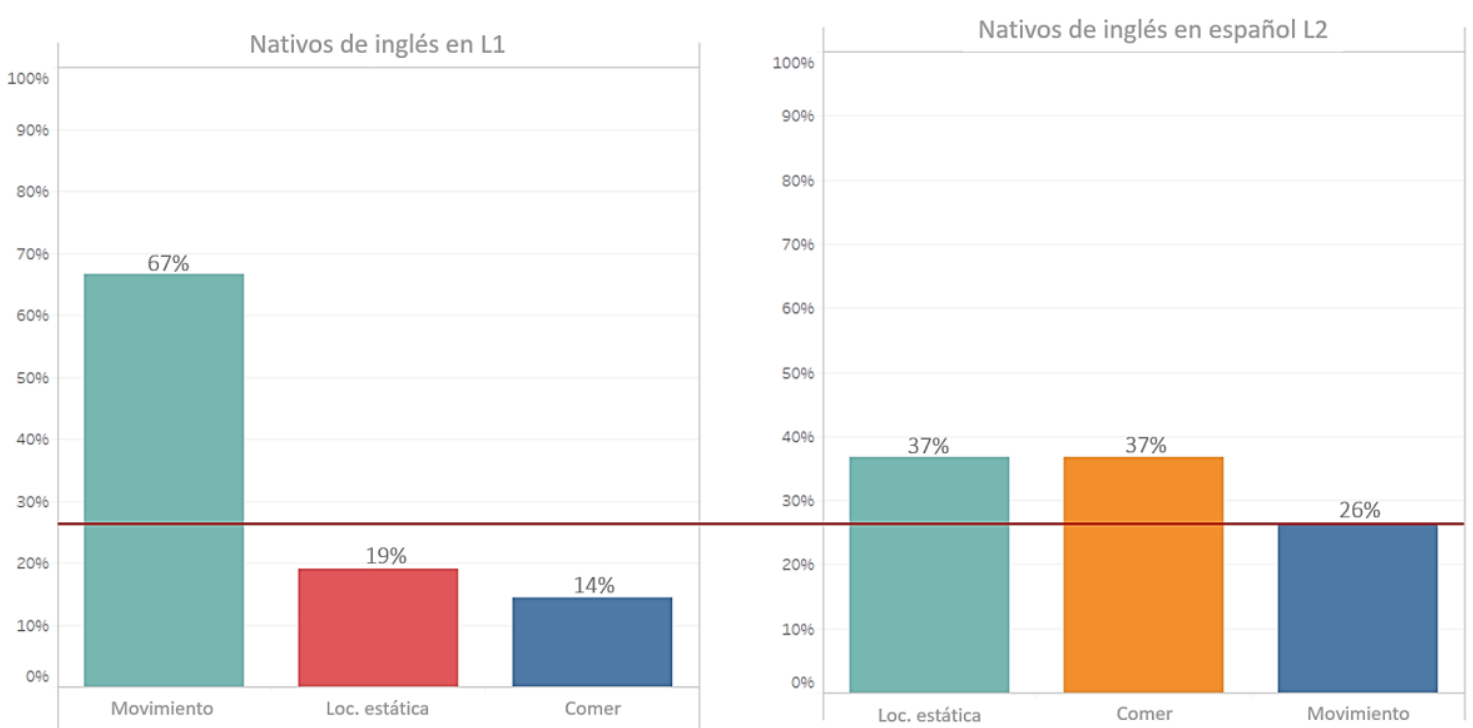

Figura 3. Interpretación de la escena en la L1 y la L2 del grupo de nativos ingleses. Medias de frecuencia en el corpus. 


\section{Nordic Journal of Modern Language Methodology}

Temanummer: Spansk i Norge og det norske i den spansktalende verden.

En cuanto al grupo de nativos noruegos, al comparar el corpus en noruego L1 con el de inglés L2 sigue dominando la preferencia a enmarcar la escena en un evento de movimiento (Figura 4), lo cual sugiere transferencia positiva desde la L1. Sin embargo, también se aprecia una reducción importante (noruego L1 78\% > inglés L2 $52 \%$ ), a la vez que aumentan las menciones a "comer" (noruego L1 9\% < inglés L2 26\%). Esto sugiere una posible dificultad subyacente a la expresión del evento de movimiento y, por lo tanto, una tendencia a evitar la expresión de este tipo de conceptualizaciones en una lengua no-nativa, incluso tratándose de una lengua del mismo grupo tipológico a la nativa.

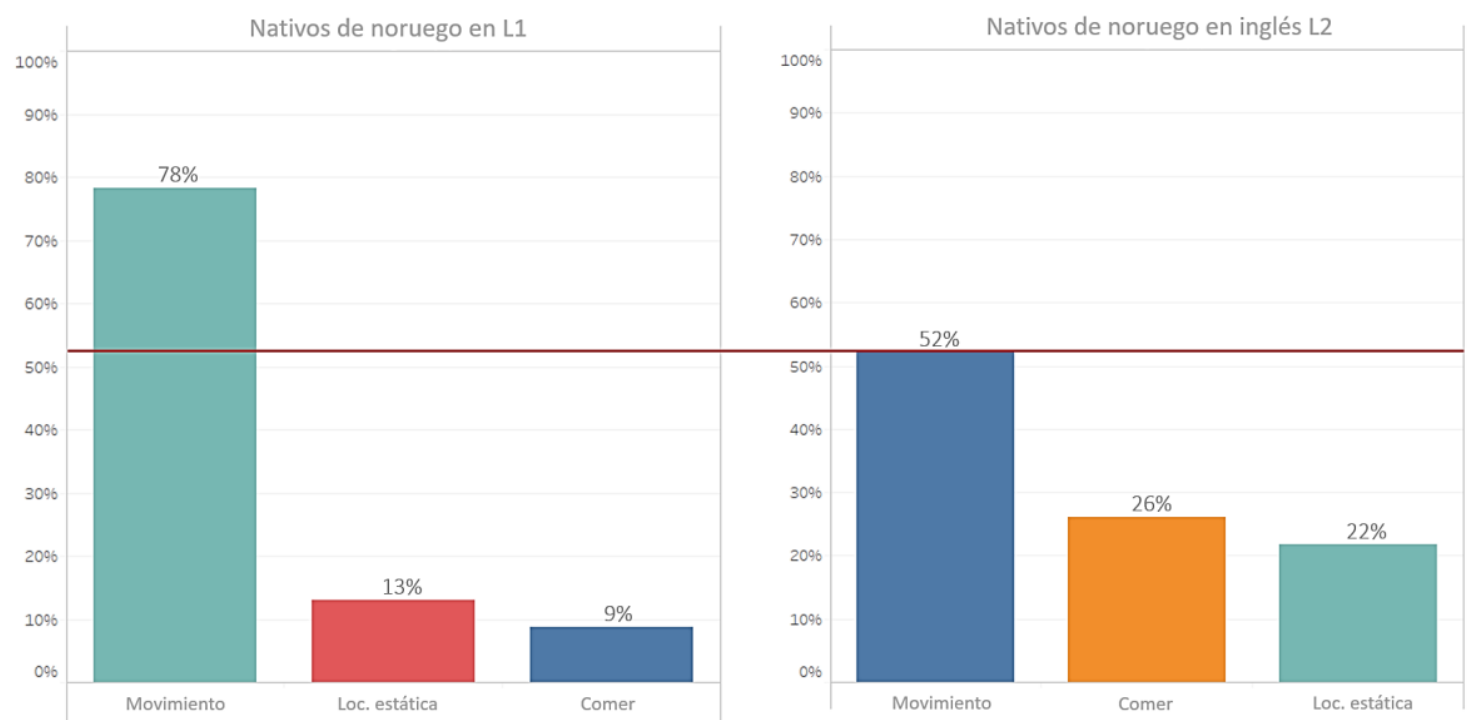

Figura 4. Interpretación de la escena en la L1 y la L2 del grupo de nativos noruegos. Medias de frecuencia en el corpus.

En el caso de las narraciones escritas en español L3, la evitación a mencionar el evento de movimiento es mucho más evidente, pues apenas tiene representación en el corpus (Figura 5). Si comparamos las narraciones en las tres lenguas de los aprendices noruegos, se aprecia la tendencia general a evitar este marco conceptual en las lenguas extranjeras (noruego L1 78\% > inglés 52\% > español L3 2\%) y a favorecer otros presuntamente más asequibles, como el de "comer" (noruego L1 14\% < inglés L2 26\% < español L3 69\%). 


\section{Nordic Journal of Modern Language Methodology}

2019, 7 (2), 89-119 Peer reviewed Temanummer: Spansk i Norge og det norske i den spansktalende verden.
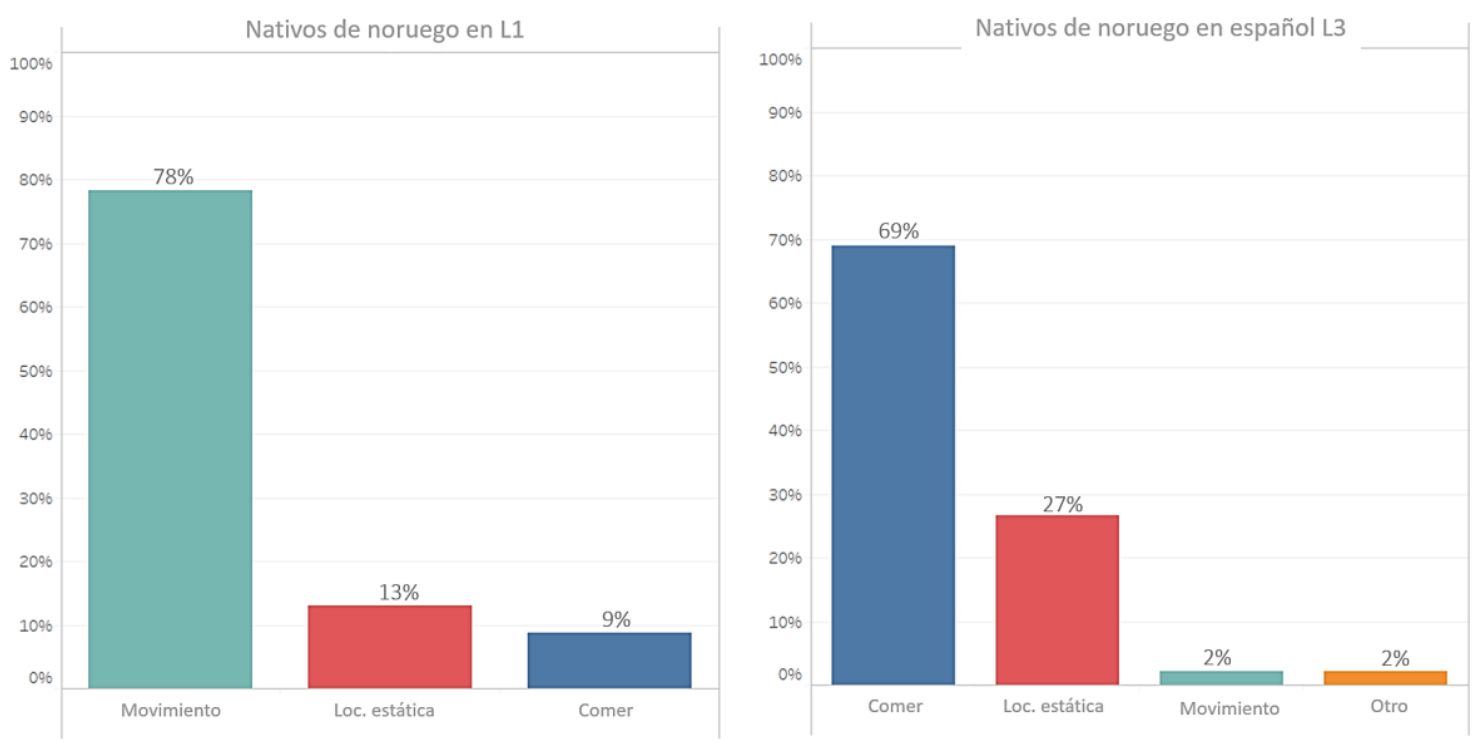

Figura 5. Interpretación de la escena en la L1 y la L3 del grupo de nativos noruegos. Medias de frecuencia en el corpus.

Por último, los hablantes nativos de español, cuando usan inglés L2, siguen mostrando la tendencia a localizar al perrito dentro de la cesta y, por lo tanto, a enmarcar la escena de manera estática (Figura 6). De hecho, hay un incremento en la frecuencia de este tipo de expresiones en la L2 (español L1 38\% < inglés 48\%). Asimismo, hay un descenso en la frecuencia de referencias a la escena como un evento de movimiento cuando se realiza en la L2 (español L1 33\% > inglés L2 22\%), lo cual es indicativo, nuevamente, de evitación y, por lo tanto, de transferencia negativa. 


\section{Nordic Journal of Modern Language Methodology}

2019, 7 (2), 89-119 Peer reviewed Temanummer: Spansk i Norge og det norske i den spansktalende verden.

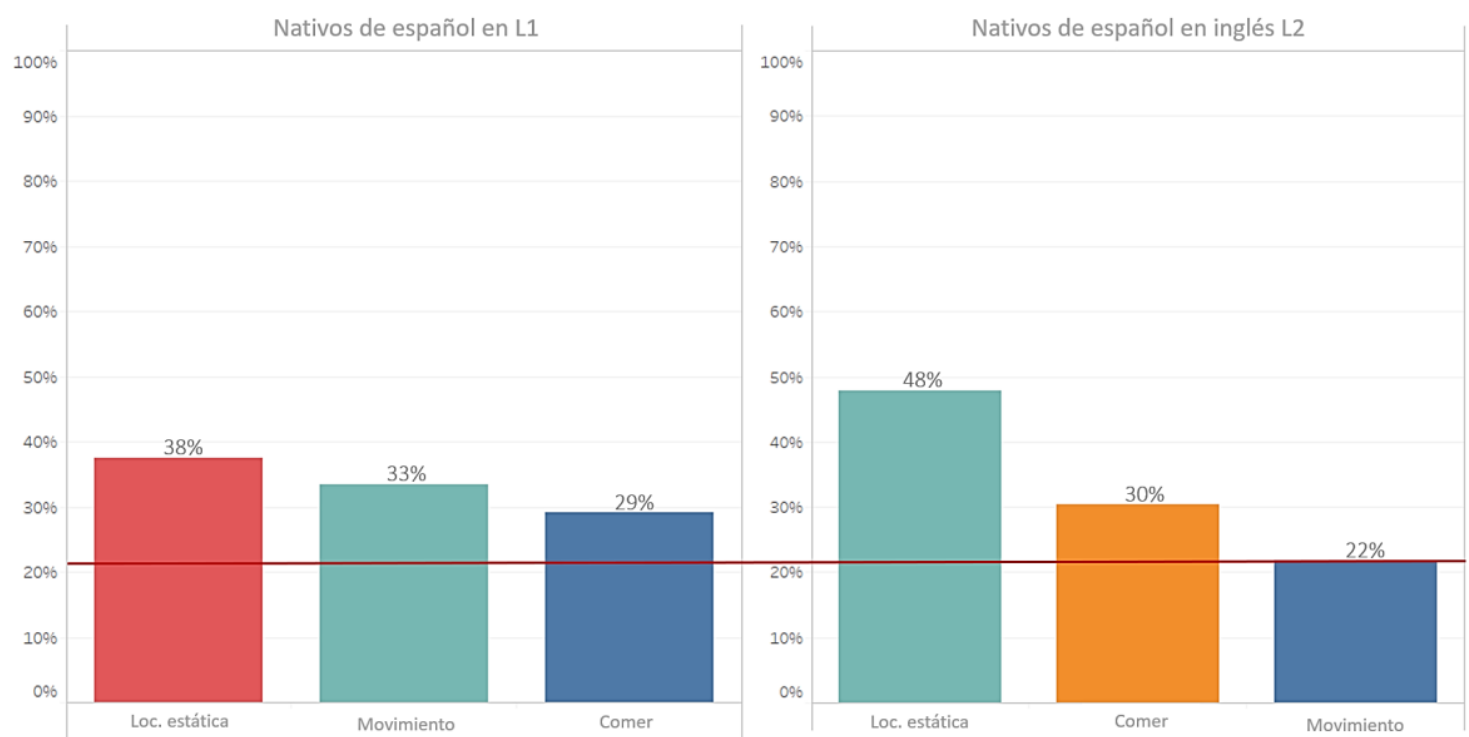

Figura 6. Interpretación de la escena en la L1 y la L2 del grupo de nativos españoles. Medias de frecuencia en el corpus.

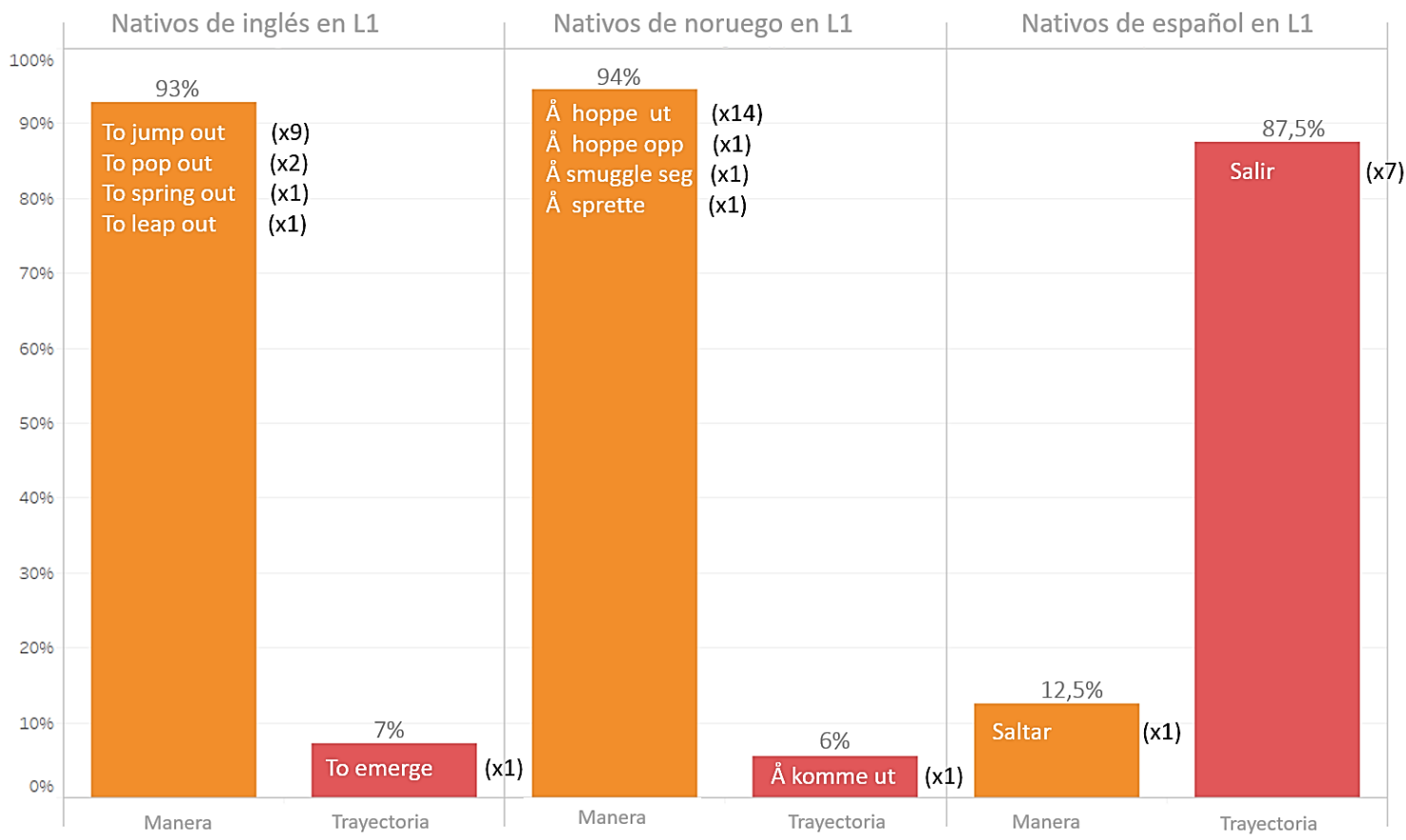

Figura 7. Verbos de manera y trayectoria de movimiento en la L1. En paréntesis, la frecuencia de cada uno de los verbos dentro de cada respectivo corpus.

P5. En los casos de uso de verbos de movimiento, ¿expresará cada grupo la trayectoria y la manera de movimiento de forma diferente en su L1?

Como vemos, todos se sienten muy cómodos a la hora de expresar eventos de movimiento en la $L 1$, pero hacerlo en una lengua extranjera les supone un reto que 


\section{Nordic Journal of Modern Language Methodology}

Temanummer: Spansk i Norge og det norske i den spansktalende verden.

tienden a evitar. Aunque la tendencia también se da en el caso de lenguas pertenecientes al mismo grupo tipológico, el salto inter-tipológico supone un reto mayor, sobre todo para los hablantes nativos noruegos, que al hacer las narraciones en español L3 evitaron totalmente hablar de movimiento. Como se vio anteriormente, las SFL suelen incluir verbos de movimiento que expresan la manera en que se realiza el movimiento, mientras que las VFL prefieren usar el verbo para marcar la trayectoria. La P5 busca confirmar esta diferencia tipológica en las narraciones producidas en las distintas L1 de nuestro corpus. Conviene recordar que los datos no se refieren a todos los informantes que contribuyeron al corpus, sino tan solo a aquellos que seleccionaron la escena para su mención y que, además, la enmarcaron como un evento de movimiento.

Como se puede observar (Figura 7), tanto los nativos de inglés como los de noruego, es decir, los representantes de alguna SFL, prefieren claramente (93\% y 94\% respectivamente) usar verbos de movimiento cuyas raíces describan la manera de movimiento. El grupo de nativos de español muestra la tendencia contraria por la que tienden a usar un verbo de movimiento que describe la trayectoria del movimiento sin especificar la manera $(87,5 \%)$. 


\section{Nordic Journal of Modern Language Methodology}

Temanummer: Spansk i Norge og det norske i den spansktalende verden.

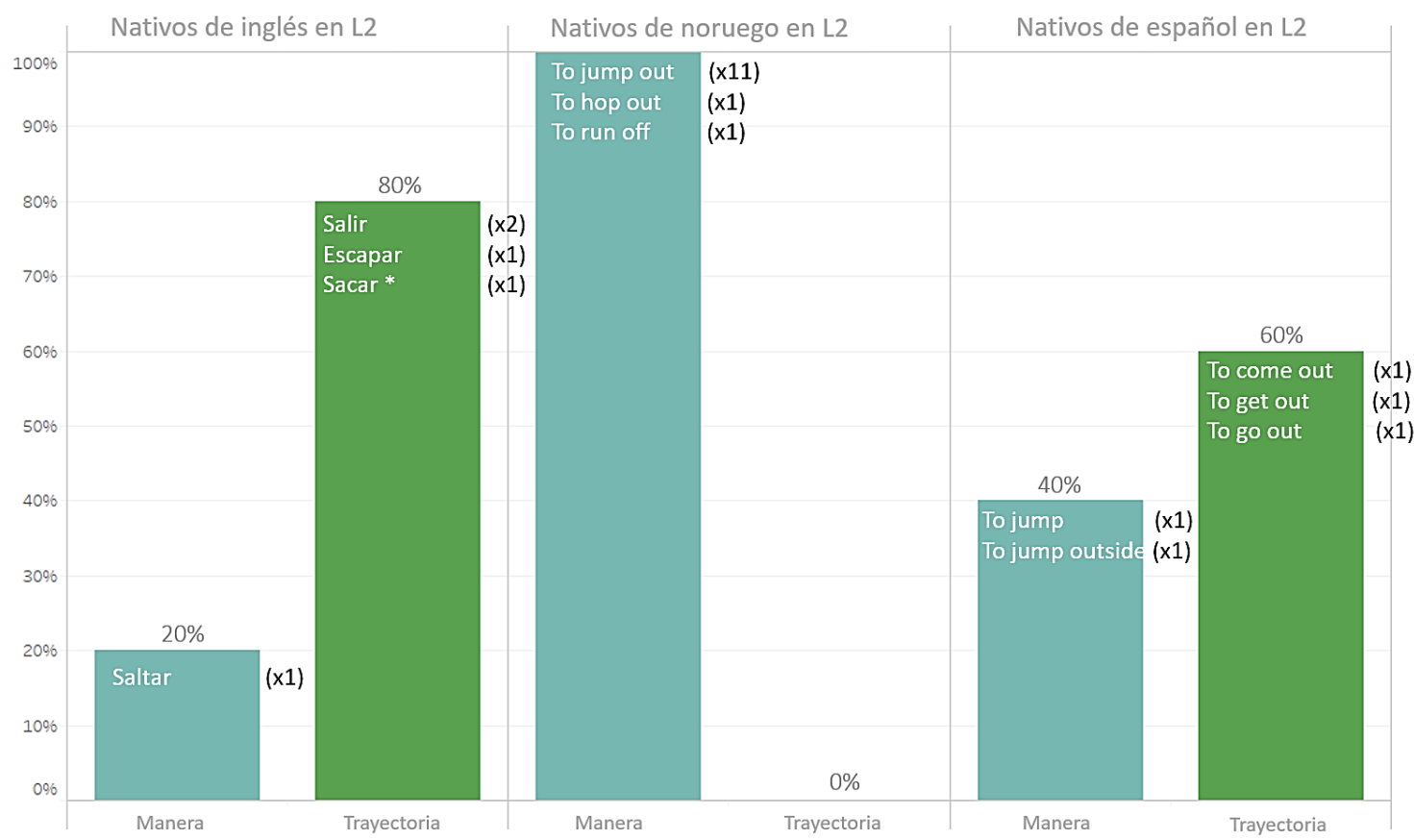

Figura 8. Verbos de manera y trayectoria de movimiento en la L2. Entre paréntesis se da la frecuencia de cada uno de los verbos dentro de cada respectivo corpus.

P6. ¿Habrá influencia interlingüística en la expresión de la trayectoria y la manera de movimiento cuando usen la L2 o la L3?

Una vez confirmada la tendencia en la L1, la P6 indaga en el uso de la L2 (Figura 8). Recordemos que los nativos noruegos evitaron casi totalmente la descripción de la escena dentro del marco de un evento de movimiento en la producción de narrativas en español L3, por lo cual no se dan datos de este grupo para la P6. En cuanto a sus narraciones escritas en inglés L2, nos encontramos con que absolutamente todos los ejemplos de verbos de movimiento incluyen el elemento semántico para describir la manera. Esto sugiere, nuevamente, la transferencia positiva que facilitan las características comunes de las SFL.

En cuanto a los nativos ingleses en español L2, observamos que, de los pocos que no evitan describir la escena como un evento de movimiento, la mayoría utiliza verbos de trayectoria en su raíz, es decir, verbos que típicamente usarían hablantes nativos de la lengua meta. Esto sugiere aprendizaje exitoso de la preferencia española, aunque, como se ve en los ejemplos (7) y (8), transfieren los 


\section{Nordic Journal of Modern Language Methodology}

2019, 7 (2), 89-119 Peer reviewed Temanummer: Spansk i Norge og det norske i den spansktalende verden.

patrones de colocación de los verbos ingleses, evidenciado por la ausencia de preposición "de":

(7) el perro es sorprendido por los vacos y sale la basketa,

(8) Tito sale la basketa y los niños no pueden comer.

En cuanto a los pocos hablantes nativos de español que no evitaron describir el evento en términos de movimiento en su narración en inglés L2, la mayoría usa verbos que marcan la trayectoria, lo cual apunta a la transferencia negativa desde la L1.

\section{Discusión e implicaciones del estudio}

El análisis de las menciones a la escena meta ofrece indicios de posibles patrones de atención diferentes en los hablantes de las distintas lenguas. El hallazgo no apunta solamente a diferencias individuales, sino que muestra tendencias grupales. Aunque la atención a una escena visual depende tanto de características inherentes a la escena en sí misma como de fenómenos cognitivos generales (Borji, Sihite, \& Itti), nuestros datos apuntan a la especificidad de la lengua nativa como factor decisivo para la saliencia de ciertos aspectos de una escena durante la producción lingüística (véase Schmid \& Günther). La tendencia es especialmente clara al comparar lenguas pertenecientes a grupos tipológicos distintos (SFL Vs VFL), aunque también se aprecian sutiles diferencias intra-tipológicas. Además, estas tendencias se dan en cualquiera de las lenguas en que los aprendices realicen la tarea, lo cual es indicio de IIL.

Desde el punto de vista de la expresión lingüística de los eventos de movimiento, vemos diferencias claras que, nuevamente, evidencian transferencia al realizar la tarea en las lenguas extranjeras. Cuando la transferencia ocurre desde una lengua fuente del mismo grupo tipológico al que pertenece la lengua meta (noruego L1 -> inglés L2), se observa transferencia positiva en la expresión de la trayectoria y la manera del movimiento. Cuando se trata de una lengua de otro grupo tipológico (noruego L1 $\rightarrow>$ español L3; inglés L1 $\rightarrow$ español L2; español L1 $\rightarrow$ inglés L2), la transferencia es negativa, resultando en la evitación de la mención del evento en términos de 


\section{Nordic Journal of Modern Language Methodology}

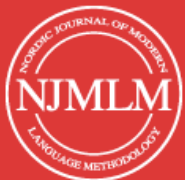

2019, 7 (2), 89-119 Peer reviewed

Temanummer: Spansk i Norge og det norske i den spansktalende verden.

movimiento, y desplazando la preferencia a otros aspectos de la escena menos exigentes para los aprendices (p. ej. localización estática).

Aunque más estudios con más participantes y con diferentes niveles de competencia lingüística son necesarios, los resultados presentados aquí conllevan ciertas implicaciones. Por una parte, lo que implica este hallazgo para los aprendices noruegos e ingleses de español L2/L3 es el reto cognitivo de restructurar los patrones de lexicalización cambiando la expresión de la trayectoria del movimiento al verbo principal. Por otra parte, en el caso de los aprendices españoles de inglés L2, se trata de inhibir el uso de verbos que sólo marquen la trayectoria de movimiento y aprender la tendencia a marcar la manera en el verbo y no en construcciones adverbiales y gerundios.

Finalmente, para los profesores de español como L2/L3 con aprendices nativos de inglés o noruego, el reto consiste en hacer visibles, durante la enseñanza, todos estos patrones lexicalizados, puesto que se trata de elementos semánticos altamente afianzados en la memoria a largo plazo (Schmid \& Günther; Ellis \& Wulff) y, por lo tanto, el contraste puede pasar desapercibido para los aprendices si no se hacen notar explícitamente.

\section{Conclusiones}

Como se ha comprobado en el estudio aquí presentado, aunque narrar es una de las capacidades lingüísticas básicas del ser humano, los procesos cognitivos y lingüísticos que requiere manifiestan gran nivel de complejidad. Los mecanismos involucrados se van formando paulatinamente durante el desarrollo biológico de los individuos y durante la socialización lingüística. Además, el proceso es paralelo e inseparable al desarrollo conceptual de los individuos. El análisis de una narración nos permite explorar el reflejo de los procesos activos en la cognición individual, pero, como hemos visto, agrupar un corpus de narraciones según las características de los hablantes, incluido el bagaje lingüístico, nos da la posibilidad de hacer comparaciones interlingüísticas individuales y grupales. Por ello, se trata de un método de gran valor para investigadores y docentes de lenguas extranjeras 


\section{Nordic Journal of Modern Language Methodology}

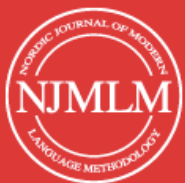

2019, 7 (2), 89-119 Peer reviewed

Temanummer: Spansk i Norge og det norske i den spansktalende verden.

interesados en comprender fenómenos que, normalmente, escapan al análisis de textos individuales, y cuya utilidad reside en su potencial para explorar cuestiones como la adquisición de estructuras lingüísticas específicas, el dominio de ciertos campos semánticos o conceptuales, o incluso la eficacia de un método de enseñanza. Hemos visto, en concreto, la utilidad del método para la investigación de la IIL, ilustrado aquí en el estudio de la transferencia de la expresión de eventos de movimiento como ejemplo de conceptualizaciones altamente afianzadas en la lengua nativa, y en los diferentes retos que los aprendices de diferentes grupos tipológicos tienen que superar para adquirir fluidez conceptual. Por último, hay que insistir en que, aunque la extracción y el análisis de narraciones requiere de rigurosas precauciones metodológicas en su diseño, este método, relativamente sencillo de implementar en el aula, permite una colaboración productiva entre docentes de diferentes lenguas extranjeras y con alumnos de diferentes lenguas nativas.

\section{Bibliografía}

Barthes, Roland. "An Introduction to the Structural Analysis of Narrative." New Literary History 6.2 (1975): 237-272. Impreso.

Borji, Ali, Dicky N Sihite, \& Laurent Itti. "What Stands out in a Scene? A Study of Human Explicit Saliency Judgment." Vision Research 91 (2013): 62-77. Web. 25 de marzo de 2018.

Cadierno, Teresa. "Expressing Motion Events in a Second Language: A Cognitive Typological Perspective." Cognitive Linguistics, Second Language Acquisition, and Foreign Language Teaching. Ed. M. Achard and S. Neimeier. Berlin: Mouton de Gruyter, 2004. 13-49. Impreso.

Cenoz, Jasone. "Cross-Linguistic Influence in Third Language Acquisition: Implications for the Organization of the Multilingual Mental Lexicon." Bulletin VALS-ASLA 78 (2003): 1-11. Impreso.

Danesi, Marcel. "Learning and Teaching Languages: The Role of 'Conceptual Fluency." International Journal of Applied Linguistics 5.1 (1995): 3-20. Web.

De Angelis, Gessica. Third or Additional Language Acquisition. Clevedon, Buffalo \& Toronto: Multilingual Matters, 2007. Impreso.

Dietrich, Jelscha Maria. "La Influencia Interlingüística En El Aprendizaje de Español Como Tercera Lengua de Aprendices Brasileños." Stockholms Universitet, 2015. 
Nordic Journal of Modern Language Methodology

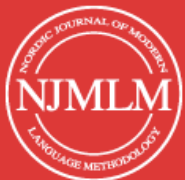

2019, 7 (2), 89-119 Peer reviewed

Temanummer: Spansk i Norge og det norske i den spansktalende verden.

Web. 25 de marzo de 2018.

Doiz, Aintzane, \& David Lasagabaster. "The Age Factor and the Acquisition of Rhetorical Aspects in a Foreign Language: Events of Motion." Rivista di Psicolinguistica Applicata 1.2 (2002): 33-50. Impreso.

Donoso, Alejandra. "Expresiones de Movimiento En Español Como Segunda Lengua y Como Lengua Heredada. Conceptualización y Entrega Del Camino, La Manera y La Base." Stockholm University 2016, 2016. Web. 25 de marzo de 2018.

Ellis, Nick C., \& Stefanie Wulff. "Usage-Based Approaches to SLA." Theories in Second Language Acquisition: An Introduction. Ed. Bill VanPatten \& Jessica Williams. Second. Routledge, 2015. 1-34. Impreso.

Filipovic, Luna, \& Iraide Ibarretxe-Antuñano. "Motion." Handbook of Cognitive Linguistics. Ed. Ewa Dabrowska and Dagmar Divjak. Berlin/ Boston: Mouton de Gruyter, 2015. 526-545. Impreso.

Fillmore, Charles J. "Frame Semantics." The Cognitive Linguistics Reader. Advances in Cognitive Linguistics. Ed. Vyvyan Evans, Benjamin K. Bergen, \& Jörg Zinken. London \& Oakville: Equinox, 2007. 239-262. Impreso.

Foster, Pauline, \& Parvaneh Tavakoli. "Native Speakers and Task Performance: Comparing Effects on Complexity, Fluency, and Lexical Diversity." Language Learning 59.4 (2009): 866-896. Web. 25 de marzo de 2018.

Grosjean, François. "The Bilingual Individual." Interpreting 2.1 (1997): 163-187. Web. 25 de marzo de 2018.

Heaton, J. B. Composition through Pictures. London: Longman, 1966. Impreso.

Jarvis, Scott. "Clarifying the Scope of Conceptual Transfer." Language Learning 66.3 (2016): 608-635. Web. 25 de marzo de 2018.

---. "Methodological Rigor in the Study of Transfer: Identifying L1 Influence in the Interlanguage Lexicon." Language Learning 50.2 (2000): 245-309. Impreso.

---. "Theoretical and Methodological Issues in the Investigation of Conceptual Transfer." Vigo International Journal of Applied Linguistics 4.43-71 (2007): 4371. Impreso.

Jarvis, Scott, \& Aneta Pavlenko. Crosslinguistic Influence in Language and Cognition. New York: Routledge, 2007. Impreso.

Kleinmann, Howard H. "Avoidance Behavior in Adult Second Language Acquisition." Language Learning 27.1 (1977). Impreso.

Lasagabaster, David, \& Aintzane Doiz. "Maturational Constraints on ForeignLanguage Written Production." Age and the Acquisition of English as a Foreign Language. Ed. M. del Pilar García Mayo \& M. Luisa García Lecumberri. Clevedon, Buffalo, Toronto \& Sydney: Multilingual Matters, 2003. 136-160. 
Nordic Journal of Modern Language Methodology

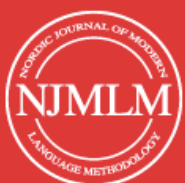

2019, 7 (2), 89-119 Peer reviewed

Temanummer: Spansk i Norge og det norske i den spansktalende verden.

Impreso.

Laufer, Batia, \& Stig Eliasson. "What Causes Avoidance in L2 Learning." Studies in Second Language Acquisition 15.01 (1993): 35-48. Web. 25 de marzo de 2018.

Licandro, Ulla. Narrative Skills of Dual Language Learners. Acquisition and PeerAssisted Support in Early Childhood Education and Care. Hannover: Springer, 2016. Impreso.

Minami, Masahiko. "Narrative, Cognition, and Socialization." The Handbook of Narrative Analysis. Ed. Anna De Fina \& Alexandra Georgakopoulou. WileyBlackwell, 2015. 76-96. Impreso.

Odlin, Terence. Language Transfer. Cross-Linguistic Influence in Language Learning. 5th ed. Cambridge: Cambridge University Press, 1989. Impreso.

Odlin, Terence, \& Scott Jarvis. "Same Source, Different Outcomes: A Study of Swedish Influence on the Acquisition of English in Finland." International Journal of Multilingualism 1.2 (2004): 123-140. Web. 25 de marzo de 2018.

Pavlenko, Aneta. "Conceptual Representation in the Bilingual Lexicon and Second Language Vocabulary Learning." The Bilingual Mental Lexicon Interdisciplinary Approaches. Ed. Aneta Pavlenko. Clevedon: Multilingual Matters, 2009. 125160. Impreso.

---. "Narrative Analysis." The Blackwell Guide to Research Methods in Bilingualism and Multilingualism. Ed. Li Wei \& Melissa Moyer. Blackwell Publishing Ltd., 2008. 311-325. Impreso.

Pearson, Barbara Zurer, \& Peter A. de Villiers. "Discourse, Narrative and Pragmatic Development." Encyclopedia of Language and Linguistics (Second Edition). Ed. K. Brown. Elsevier, 2006. 686-693. Web. 30 de octubre de 2017.

Peterson, C., \& A. McCabe. "Linking Children's Connective Use and Narrative Macrostructure." Developing Narrative Structure. Ed. A. McCabe \& C Peterson. Hillsdaly, New Jersey: Lawrence Erlbaum Associates, 1991. 29-53. Impreso.

Saeedi, Masoud. "The Influence of Strategic Planning and Storyline Complexity on EFL Learners' Narrative Retellings." The Journal of Language Teaching and Learning 1 (2013): 20-36. Web. 17 de julio de 2017.

Sánchez, Laura. "L2 Activation and Blending in Third Language Acquisition: Evidence of Crosslinguistic Influence from the L2 in a Longitudinal Study on the Acquisition of L3 English." Bilingualism: Language and Cognition 18.02 (2015): 252-269. Web. 25 de marezo de 2018.

Sánchez, Laura, \& Scott Jarvis. "The Use of Picture Stories in the Investigation of Crosslinguistic Influence." Teachers of English to Speakers of Other languages 42.2 (2008): 329-333. Impreso.

Schmid, Hans-Jörg, \& Franziska Günther. "Toward a Unified Socio-Cognitive 


\section{Nordic Journal of Modern Language Methodology}

2019, 7 (2), 89-119 Peer reviewed Temanummer: Spansk i Norge og det norske i den spansktalende verden.

Framework for Salience in Language." Frontiers in Psychology 7.AUG (2016): 58. Web. 25 de marzo de 2018.

Talmy, Leonard. "Attention Phenomena." The Oxford Handbook of Cognitive Linguistics. Ed. Dirk Geeraerts \& Hubert Cuyckens. Oxford: Oxford University Press, 2007. 264-293. Impreso.

---. Toward a Cognitive Semantics. Vol. 1 \& 2. Cambridge, Massachusetts; London, England: The MIT Press, 2000. Impreso.

Tavakoli, Parvaneh, \& Pauline Foster. "Task Design and Second Language Performance: The Effect of Narrative." Language Learning 61.June (2008): 439_ 473. Web. 25 de marzo de 2018.

Von Stutterheim, Christiane, \& Ralf Nüse. "Processes of Conceptualization in Language Production: Language-Specific Perspectives and Event Construal." Linguistics 5.41 (2003): 851-881. Web. 25 de marezo de 2018. 


\section{Nordic Journal of Modern Language Methodology}

2019, 7 (2), 89-119 Peer reviewed

Temanımmer. Snanck i Norre no det nnrcke i den cnancktalende verden

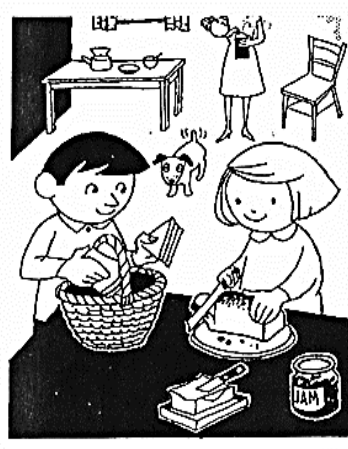

1

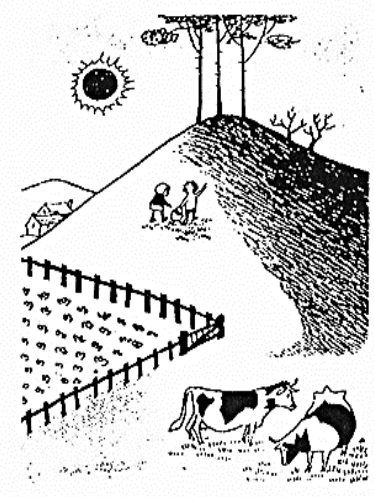

4

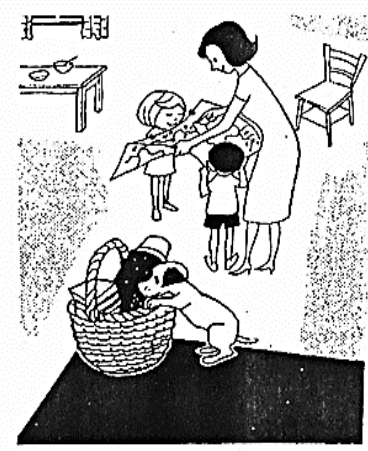

2

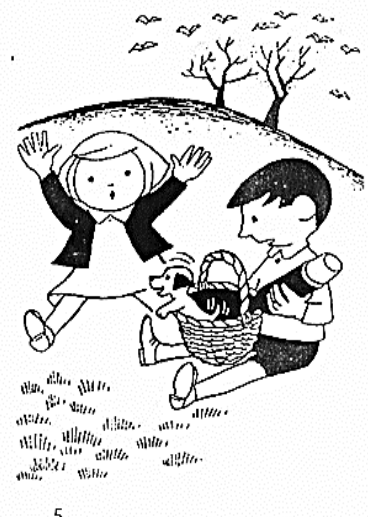

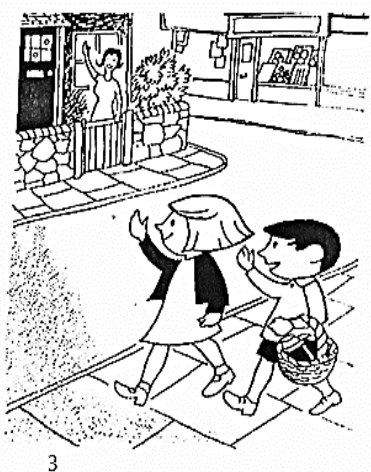

3

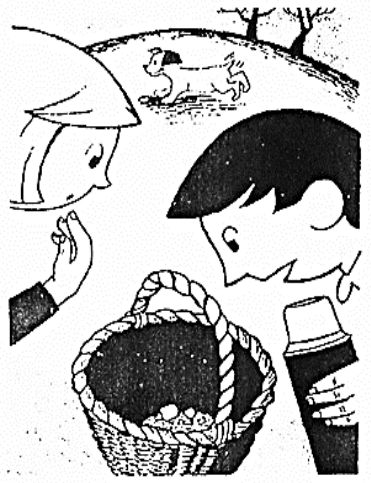

